\title{
COMPARATIVE EVALUATION OF THE ANTIBACTERIAL EFFECT OF TRIPLE ANTIBIOTIC PASTE VERSUS PROPOLIS AS INTRACANAL MEDICAMENT
}

\author{
Elsaeed Abdel Hafez * and Amgad H . Soliman *
}

\begin{abstract}
Purpose: This study aimed to compare between Propolis and Triple Antibiotic Paste as root canal medicaments in eradication of Enterococcus faecalis. Material and Methods: for this study, 60 extracted human teeth were used. After their decapitation, they were initially instrumented to reach $20 \mathrm{~K}$-file, later they were separated into 2 sets according to the medicament used; Group A1: Triple antibiotic paste Group A2: Propolis paste (30 specimens in each group). After sterilization of all samples inoculation was performed with Enterococcus faecalis (ATCC29212) over a period of 21 days. Preparation of all samples was done using Step- back technique to reach \#50 file, irrigation using sodium hypochlorite solution of $2.6 \%$ concentration and EDTA, then intracanal medicaments were applied. First sample (S1) was collected after inoculation of bacteria into root canals. Second sample (S2) was collected after undergoing instrumentation and irrigation. Third sample (S3) was taken following application of medicament. Fourth sample (S4) was taken following application of sterile cotton pellet and temporary restoration for seven days. BHI agar was used for culturing of samples then went under incubation to count CFU's. Results: There was a significant difference between different samples where $(\mathrm{p} \leq 0.05)$ and there was a continuous decrease of (mean $\pm \mathrm{SD})$ value starting from (S1) till (S4). Pairwise comparisons for both medicaments showed all samples to be significantly different from each other. Conclusion: Antimicrobial activity of Propolis against E. faecalis was found to be greater than that of TAP and can be used as a short-term intracanal medicament.
\end{abstract}

Keywords: Propolis, Triple antibiotic paste, Intracanal medicament, Enterococcus faecalis.

\section{INTRODUCTION}

Bacteria and bacterial toxins are of the main causative agent of pulpal necrosis and lesions in the periapical area. Endodontic infections have a polymicrobial nature that's why endodontic failure is primarily associated with anaerobic and facultative anaerobic microorganisms ${ }^{(1)}$. Enterococcus faecalis

Taking into account the complex anatomy of root canal systems, chemomechanical preparation does not completely eradicate the bacteria. Therefore, the use of intracanal medicament between

\footnotetext{
* Lecturer of Endodontics, Faculty of Oral and Dental Medicine, Future University- Egypt.
} 
appointments plays a hugely significant rule in root canal disinfection. It helps in prevention of growth of resistant strains and removal of smear layer. It should be non-antigenic, nontoxic and doesn't have carcinogenic properties. Furthermore it shouldn't have adverse effect on dentin or sealing ability of obturating materials. In addition it should be inexpensive, convenient to apply and doesn't cause tooth discoloration. Other desirable properties for an ideal medicament include the ability to dissolve pulp tissue and inactive endotoxins ${ }^{(2)}$.

Calcium hydroxide has been repeatedly and intensely used as intracanal medicament for its antimicrobial characters, its potentials in dissolving organic materials and its power of bacterial endotoxin inactivation. It has the ability to inhibit bacterial metabolic activity, growth, and cellular division due to its high PH. By disrupting the organic components and nutrients' transport, thus altering the integrity of cytoplasmic membrane. Despite its excellent properties, calcium hydroxide does not have the same effect over different microorganisms inside root canals. Many different studies came to the conclusion that calcium hydroxide does not have strong effect against Enterococcus faecalis, which is a kind of bacteria that is highly resistant to a huge number of antimicrobial agents because of a variety of defense mechanisms, and it's repeatedly found in teeth after failure treatment of root canals ${ }^{(3)}$. The drawbacks of calcium hydroxide have promoted researchers to look for alternative agents.

In combination with endodontic treatment we often use antibiotics, to increase its efficacy we resort to intracanal application instead of systemic route of administration. Studies show the efficacy of Triple antibiotic paste (TAP) as antimicrobial agent against microorganisms found within root canal system among which is E. faecalis, TAP contains ciprofloxacin, metronidazole, and minocycline. Minocycline present in TAP has the only drawback of causing tooth staining ${ }^{(4)}$.
Propolis (Bee glue), a very promising material used in herbal medicine, is collected by bees from plants or young shoots and barks of trees. It is a natural remedy that can be used to cure various diseases. Its major active components are flavonoids and cinnamic acid derivatives. Ethanolic extract of Propolis can provoke bone regeneration and induce hard tissue bridge formation. Recent reports of the biological effects of Propolis indicated that it has antimitotic, antioxidant, anti-fungal, anti-viral, anti-inflammatory, anti-tumor and antimicrobial activities, which have been utilized clinically, both systemically and topically. The most recent studies concluded that the effectiveness of Propolis against microorganisms which are highly resistant was found to be more compatible to the periradicular tissues than popular intracanal medicaments. On the other hand, only few studies looked into efficacy of Propolis as intracanal medicament; therefore, the aim of this study was directed to hold a comparison between the antibacterial effect of Triple antibiotic paste compared to Propolis in eradication of $\mathrm{E}$. faecalis.

\section{MATERIALS AND METHODS}

\section{Sample selection and preparation:}

For this study, 60 single rooted extracted human teeth with single canal were chosen with mature apices. Confirmation of the presence of single canal were done by radiographic images of both the mesio-distal and bucco-lingual directions. After that, by the use of ultrasonic scaler, the teeth were properly washed of deposits and soft tissue. A standard root length of $15 \mathrm{~mm}$ was considered by decoronation of the tooth perpendicular to the long axis by a diamond disc. A $20 \mathrm{~K}$-file size was initially instrumented for all samples then separated into 2 groups according to the medicament used; Group A1: Triple antibiotic paste Group A2: Propolis paste (30 specimens in each group). All samples were sterilized using gamma radiation (Cobalt 60 irradiators with dose rate of $1.774 \mathrm{KGY}$ with total dose of $25 \mathrm{KGY}$ ). 


\section{Biofilm development and canal inoculation:}

Sterilized brain heart infusion broth was used as a media for propagation of Enterococcus faecalis (ATCC 29212) was incubated for 24 hours at $37^{\circ} \mathrm{C}$ in anaerobic chamber. The bacterial concentration was adjusted to $1.5 \times 10 * 8 \mathrm{CFU} / \mathrm{ml}$ which is the equivalent to \#0.5 McFarland turbidity level. All specimens were inoculated by $0.5 \mathrm{~mL}$ of the suspension using $1 \mathrm{ml}$ insulin syringe. Sterile size \#15 K file was used in an up and down movement to reach the working length of bacterial suspension. Root canal orifices then subsequently covered with aseptic tin foil to avoid seepage of the microbial suspension, then placed in sterile Eppendorf tubes and held vertically in perforated trays, and held for 21 days in an incubator at $37^{\circ} \mathrm{C}$, with renewing the medium every 3 days. The excess broth was eliminated from the root canal with paper points at the end of incubation period, and the first microbial sample (S1) was taken.

\section{Completion of root canal preparation and medi- cament application:}

Step- back technique was used for the preparation of all tooth to a size \#50 file, and for the irrigation, $2.6 \%$ sodium hypochlorite $(\mathrm{NaOCl})$ solution and EDTA were used. Sterile paper points were used to prepare all root canals after irrigation, then steps for (S2) collection were followed. Then the tested medicaments (Triple antibiotic paste and Propolis) were introduced into the root canals and steps for (S3) collection were followed. The orifices of the canals were sealed with sterile cotton pellet and intermediate restoration and then, incubated at $37^{\circ} \mathrm{C}$ for 7 days after which (S4) was taken.

\section{Bacterial sampling:}

All bacterial samples were collected by injecting the canals with sterile saline using $1 \mathrm{ml}$ insulin syringe. A new sterile \#20 H-file was used to gently scrap the canal walls to derange contents of the canal, then for 1 minute, paper points (3) were put inside the canal. In a test tube in which there was I $\mathrm{ml}$ of saline solution, paper points were placed, and shaked for 30 seconds. After 10 fold serial dilutions in saline, $0.1 \mathrm{ml}$ from each dilution was smeared to be inoculated on surface of the plate media (BHI agar) and incubated at $37^{\circ} \mathrm{C}$ for $48 \mathrm{hrs}$. Then Colony Forming Units per $1 \mathrm{ml}$ were enumerated.

\section{Statistical Analysis:}

Presentation of the data was in the form of Mean, Standard deviation (SD) values. Using Kolmogorov-Smirnov and Shapiro-Wilk tests, data were explored for normality and were found to follow normal distribution and to be positively skewed so log transformation was made. Intergroup comparisons were done using Independent t-test. While intragroup comparisons were done using one-way repeated measures ANOVA followed by Bonferroni post hoc test when the main test was significant. The significance level was set at $\mathrm{P} \leq$ 0.05 for all tests. Statistical analysis was performed with IBM ${ }^{\circledR}$ SPSS ${ }^{\circledR}$ (SPSS Inc., IBM Corporation, NY, USA) Statistics Version 25 for Windows.

\section{RESULTS}

\section{Descriptive statistics:}

For both medicaments, the difference between different samples where $(\mathrm{p} \leq 0.05)$ and there was a continuous decrease of (mean $\pm \mathrm{SD}$ ) value starting from (S1) (10.01 $\pm 1.27 \mathrm{~A})$ till (S4) $(0.54 \pm 1.12 \mathrm{D})$, which was extremely significant. Pairwise comparisons for both medicaments showed all samples to be significantly different from each other (Fig 1,2).

\section{i) Group I (Triple antibiotic paste):}

The mean and standard deviation of the total bacterial count for initial sample (S1) were $(10.01 \pm 1.27)$, for post instrumentation and irrigation samples (S2) were $(4.49 \pm 1.11)$, for immediate medicament application (S3) were $(4.25 \pm 1.11)$, 
and for 7-days medicament application (S4) were $(0.54 \pm 1.12)$, there was a statistically significant difference among S1, S2, S3 and S4 in the total bacterial count $(\mathrm{p} \leq 0.05)$.

\section{ii) Group II (Propolis paste):}

The mean and standard deviation of the total bacterial count for initial sample (S1) were $(9.71 \pm 1.34)$, for post instrumentation and irrigation samples (S2) were $(4.02 \pm 1.16)$, for immediate medicament application (S3) were (3.67 \pm 1.16$)$, and for 7-days medicament application (S4) were $(0.13 \pm 0.39)$, there was a statistically significant difference among S1, S2, S3 and S4 in the total bacterial count $(\mathrm{p} \leq 0.05)$.

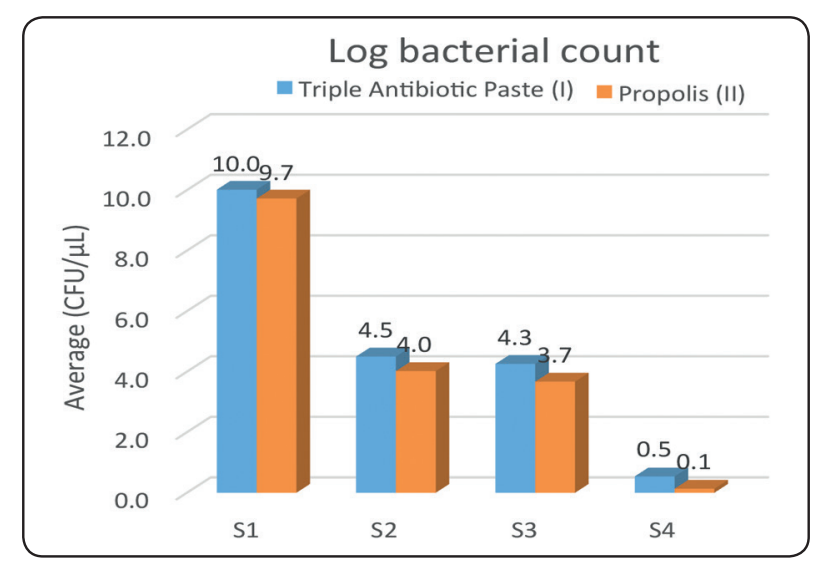

Fig. (1) Bar chart showing average Log bacterial count (CFU/ $\mu \mathrm{L}$ ) for both medicaments within different samples

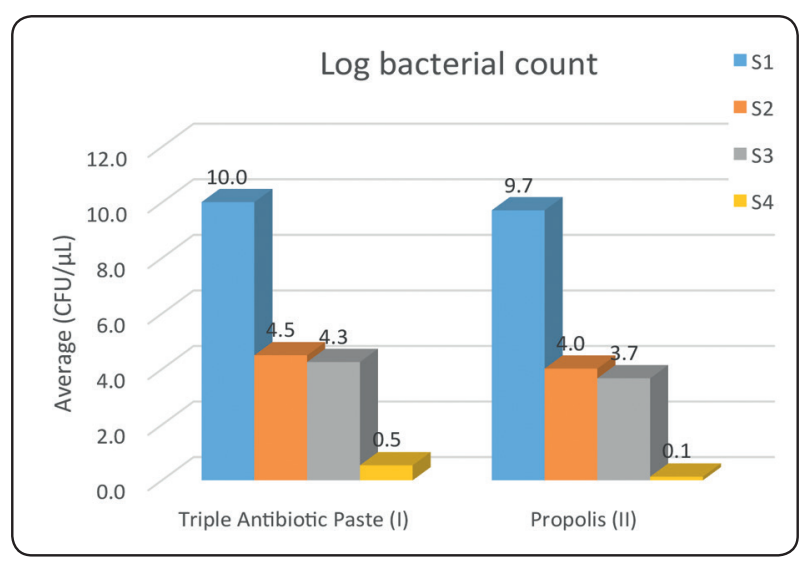

Fig. (2) Bar chart showing average Log bacterial count (CFU/ $\mu \mathrm{L}$ ) for different samples within both medicaments

\section{DISCUSSION}

Long-term success in endodontic treatment relies essentially on complete debridement of the pulpal space. By application of cleaning and shaping protocol, the bacterial populations are eliminated, as well as dead tissue. The complexity of the anatomical structure of root canal system stands as a roadblock in achieving its complete debridement. Persistence of microorganisms in the tubules in the dentinal system is the cause of ongoing infection. Thus, the application of the intracanal medicaments between appointments can be of assist in eliminating the residual bacterial content even after irrigation and instrumentation, it is also capable of providing suitable media for helping tissue repair ${ }^{(5,6)}$; Therefore, the present study aimed to hold a comparison between the antibacterial effect of Triple antibiotic paste versus Propolis in eradication of E. faecalis.

This study showed that the mechanical and antimicrobial properties of both instrumentation and irrigation (S2) for both groups could significantly reduce the number of bacteria from infected root canal where $(p<0.001)$, the mean value of bacterial count for Triple antibiotic paste (I) was $4.49 \pm 1.11$ and it was $4.02 \pm 1.16$ for Propolis (II), there is no significance in the difference between the two sets.

This result may be due to chemomechanical preparation (instrumentation and irrigation) has a massive importance in disinfection of root canal, as it significantly reduces bacterial populations by acting principally on the main canal. By washing out necrotic tissue and debris, chemomechanical preparation assists the cleaning of root canal. During negotiation and cutting it acts as an instrumental lubricant thus, preventing apical accumulation of debris. It also removes the smear layer ${ }^{(7)}$.

The result of this study shows that immediate application of both medicaments (S3) could significantly reduce the number of bacteria where $(p<0.001)$, the highest mean value of bacterial count 
was found in Triple antibiotic paste (I) $(4.25 \pm 1.11)$ with less antibacterial effect while the least mean value of bacterial count was found in Propolis (II) $(3.67 \pm 1.16)$ with higher antibacterial effect.

The reasons for these results may be due to Propolis' main components are phenolic compounds, which include many flavonoids, aromatic acids, and their esters. The pharmacological and the antimicrobial action of Propolis is attributed to its flavonoid content which exhibits its action through inhibiting the synthesis of DNA or RNA in bacteria ${ }^{(8,9)}$.

The result of the present study agrees with observation of that of the investigations held for the comparison between Propolis and non-setting calcium hydroxide paste against $E$. faecalis when used as a short-term medication for the first and second days of application. Findings implemented that Propolis' effectiveness was greater than nonsetting calcium hydroxide in fighting E. faecalis after short-term application ${ }^{(10)}$.

To verify E.faecalis recanalization and evaluate the residual effect of medicaments, (S4) was taken after 7 days from application of medicaments inside the canal and sealing the tooth with intermediate filling, as this period commonly used between appointments which corroborate others ${ }^{(11)}$. The result demonstrated that both groups could significantly reduce the number of bacteria from infected root canal where $(\mathrm{p}<0.001)$, the mean value of bacterial count for Triple antibiotic paste (I) was $0.54 \pm 1.12$ and it was $0.13 \pm 0.39$ for Propolis (II), the difference between the two groups is nonsignificant.

These results might be attributed to the metronidazole component of the TAP which is the most pharmacologically effective component in E. faecalis eradication; exerting its action through sustained release of its component ${ }^{(12)}$.

Another cause for delayed action of TAP may be due to the use of antibiotics, even topically, has led to concerns about bacterial resistance to intracanal medicaments ${ }^{(13)}$.
On the other hand, these findings are in contradiction with the results reached by another study in which the TAP exhibited a much lower percentage of living bacteria when compared with the $2 \%$ chlorhexidine gel and calcium hydroxide in the immediate and second day assessment. TAP was the best in eradicating bacteria when compared with $2 \%$ chlorhexidine gel and calcium hydroxide ${ }^{(14)}$.

The results of the current study agree with observations of studies which stated that TAP and Propolis, had the same antibacterial activity against E. faecalis on day seven of application as intracanal medication. The pharmacological action of minocycline is mainly bacteriostatic with a variety of action in fighting both Gram positive and Gram negative bacteria by interfering with protein synthesis of the organism. The pharmacological action of ciprofloxacin is mainly bactericidal action and is extremely more effective against Gram negative bacteria ${ }^{(15,16)}$.

Another study examined the antibacterial effects of a TAP on Escherichia coli within the root canal system and concluded that it can remove all target bacteria from the root canal within 48 hours. In the present study, the target bacterium was E. faecalis and its standard strain of 29212 was selected. This difference in target bacteria could be one of the reasons for the difference between our results and those of this study ${ }^{(17)}$.

\section{REFERENCES}

1- Gomes BP, Pinheiro ET, Gadê-Neto CR, Sousa ELR, Ferraz CCR, Zaia AA etal. Microbiological examination of infected dental root canals. Oral Microbiol Immunol 2004; 19:71-6.

2- Bysrorm A, Claesson R, Sundqvist G.The antibacterial effect of calcium hydroxide in the treatment of infected root canal. Endod dental Traumatol 2010; 1:170-5.

3- Tanomaru JM, Leonardo MR, Tanomaty Filho M, Bonetti Filho I, Siva LA. Effect of different irrigation solutions and calcium hydroxide on bacterial LPS. Int Endod J. 2013; 36:733-9. 
4- Jong HK, Yuram K, Shei SJ, Jeong WP, Jung IY. Tooth discoloration of immature permanent incisor associated with triantibiotic paste therapy. A case report. J Endod 2010; 36:1086-91.

5- Sassone LM, Fidel RA, Murad CF, Fidel SR. Antimicrobial activity of sodium hypochlorite and chlorhexidine by two different tests. Aust Endod J 2008; 34: 19-24.

6- Kandaswamy D, Venkateshbabu N, Gogulnath D, Kindo A. Dnetinal tubules disinfection with $2 \%$ chlorhexidine gel, propolis, morinda citrifolia juice, $2 \%$ povidone iodine, and calcium hydroxide. Int Endod J. 2010; 43:419-23.

7- Hoedke D, Enseleit C, Gruner D, Dommisch H. Effect of photodynamic therapy in combination with various irrigation protocols on an endodontic multispecies biofilm ex vivo. Int Endod J 2018; 51: e23-e34.

8- Uzel A, Kadriye S, Onçag O, Çogulu D, Gençay O, Salih B. Chemical compositions and antimicrobial activities of four different Anatolian propolis samples. Microbiol Res 2005; 160: 189-95.

9- Zohreh A, Mandana N, Farzaneh V. Propolis: Chemical Composition and Its Applications in Endodontics. Irani Endod J 2018;13: 285-92.

10- Lama A, Maha B,Mohammad H. Effectiveness of propolis and calcium hydroxide as a short-term intracanal medicament against Enterococcus faecalis: A laboratory study. Aust Endod J 2009; 35: 52-8.

11- Menezes M, Valera M, Jorge O. In vitro evaluation of the effectiveness of irrigants and intracanal medicaments on microorganisms within root canals. Int Endod J 2004; 37:311-9.

12- Adl A, Shojaee NS, Motamedifar M. A comparison between the antimicrobial effects of triple antibiotic paste and calcium hydroxide against Entrococcus faecalis. Iran Endod J 2012; 7:149-55.

13- Ghabraei S, Marvi M, Bolhari B, Bagheri P. Minimum Intracanal Dressing Time of Triple Antibiotic Paste to Eliminate Enterococcus Faecalis (ATCC 29212) and Determination of Minimum Inhibitory Concentration and Minimum Bactericidal Concentration: An Ex Vivo Study. J Dent (Tehran). 2018; 15:1-9.

14- Zapata R, Bramante C, Minotti P, Cavenago B. Antimicrobial activity of Triple antibiotic paste, $2 \%$ Chlorhexidine gel, and Calcium Hydroxide on an intraoralinfected dentin biofilm model. J Endod 2013; 39:115-8.

15- Madhubala MM, Srinivasan N, Ahmad S. Comparative evaluation of Propolis and triantibiotic mixture as an intracanal medicament against Enterococcus faecalis. J Endod 2011; 37:1287-9.

16- Hoshino E, Kurihara-Aando N, Sato I, Uematsu H, Sato M, Kota K. In-vitro antibacterial susceptibility of bacteria taken from infected root dentin to a mixture of ciprofloxacin, metronidazole and minocycline. Int Endod J 1996; 29:125-30.

17- Sato I, Ando-Kurihara N, Kota K, Iwaku M, Hoshino E. Sterilization of infected root-canal dentine by topical application of a mixture of ciprofloxacin, metronidazole and minocycline in situ. Int Endod J. 1996; 29:118-24. 